\title{
Pharmacokinetic role of protein binding of mycophenolic acid and its glucuronide metabolite in renal transplant recipients
}

\author{
Brenda C. M. de Winter • Teun van Gelder • \\ Ferdi Sombogaard • Leslie M. Shaw • \\ Reinier M. van Hest $\cdot$ Ron A. A. Mathot
}

Received: 1 July 2009/Accepted: 25 October 2009/Published online: 11 November 2009

(C) The Author(s) 2009. This article is published with open access at Springerlink.com

\begin{abstract}
Mycophenolic acid (MPA), the active compound of mycophenolate mofetil (MMF), is used to prevent graft rejection in renal transplant recipients. MPA is glucuronidated to the metabolite MPAG, which exhibits enterohepatic recirculation (EHC). MPA binds for $97 \%$ and MPAG binds for $82 \%$ to plasma proteins. Low plasma albumin concentrations, impaired renal function and coadministration of cyclosporine have been reported to be associated with increased clearance of MPA. The aim of the study was to develop a population pharmacokinetic model describing the relationship between MMF dose and total MPA (tMPA), unbound MPA (fMPA), total MPAG (tMPAG) and unbound MPAG (fMPAG). In this model the correlation between pharmacokinetic parameters and renal function, plasma albumin concentrations and cotreatment with cyclosporine was quantified. tMPA, fMPA, tMPAG and fMPAG concentration-time profiles of renal transplant recipients cotreated with cyclosporine $(n=48)$ and tacrolimus $(n=45)$ were analyzed using NONMEM. A 2- and 1-compartment model were used to describe the pharmacokinetics of fMPA and fMPAG. The central compartments of fMPA and fMPAG were connected with an albumin compartment allowing competitive binding (bMPA and bMPAG). tMPA and tMPAG were modeled as the sum of the bound and unbound concentrations. EHC was modeled by transport of fMPAG to a separate gallbladder compartment. This transport was decreased in case of
\end{abstract}

B. C. M. de Winter · T. van Gelder · F. Sombogaard · R. M. van Hest · R. A. A. Mathot ( $₫)$ Department of Hospital Pharmacy, Erasmus University Medical Center, 's-Gravendijkwal 230, 3015CE Rotterdam, The Netherlands

e-mail: r.mathot@erasmusmc.nl

T. van Gelder

Internal Medicine, Erasmus University Medical Center, Rotterdam, The Netherlands

L. M. Shaw

Department of Pathology and Laboratory Medicine, University of Pennsylvania Medical Center, Philadelphia, PA, USA 
cyclosporine cotreatment $(P<0.001)$. In the model, clearance of fMPAG decreased when creatinine clearance $(\mathrm{CrCL})$ was reduced $(P<0.001)$, and albumin concentration was correlated with the maximum number of binding sites available for MPA and MPAG $(P<0.001)$. In patients with impaired renal function cotreated with cyclosporine the model adequately described that increasing fMPAG concentrations decreased tMPA AUC due to displacement of MPA from its binding sites. The accumulated MPAG could also be reconverted to MPA by the EHC, which caused increased tMPA AUC in patients cotreated with tacrolimus. Changes in CrCL had hardly any effect on fMPA exposure. A decrease in plasma albumin concentration from 0.6 to $0.4 \mathrm{mmol} / \mathrm{l}$ resulted in ca. $38 \%$ reduction of tMPA AUC, whereas no reduction in fMPA AUC was seen. In conclusion, a pharmacokinetic model has been developed which describes the relationship between dose and both total and free MPA exposure. The model adequately describes the influence of renal function, plasma albumin and cyclosporine co-medication on MPA exposure. Changes in protein binding due to altered renal function or plasma albumin concentrations influence tMPA exposure, whereas fMPA exposure is hardly affected.

Keywords Mycophenolic acid · Population pharmacokinetics · Protein binding · Renal transplant recipients · Mechanism-based pharmacokinetic model

$\begin{array}{ll}\text { List of symbols } \\ \text { MPA } & \text { Mycophenolic acid } \\ \text { MPAG } & \text { Mycophenolic acid glucuronide } \\ t & \text { Total concentration } \\ f & \text { Unbound concentration } \\ \mathrm{T}_{\mathrm{LAG}} & \text { Lag-time } \\ \mathrm{k}_{\mathrm{a}} & \text { First order absorption rate constant } \\ \mathrm{V}_{\mathrm{c}} & \text { Central volume } \\ \mathrm{CL} & \text { Clearance } \\ \mathrm{V}_{\mathrm{p}} & \text { Peripheral volume } \\ \mathrm{Q} & \text { Intercompartmental clearance } \\ \mathrm{k}_{\mathrm{nm}} & \text { Rate constant between compartment } \mathrm{n} \text { and } \mathrm{m} \\ \mathrm{B}_{\mathrm{MAX}} & \text { Maximum number of protein binding sites } \\ \mathrm{T}_{\mathrm{GB}} & \text { Time of gallbladder emptying } \\ \mathrm{D}_{\mathrm{GB}} & \text { Duration of gallbladder emptying } \\ \mathrm{IPV} & \text { Interpatient variability } \\ \mathrm{CrCL} & \text { Creatinine clearance } \\ \mathrm{CsA} & \text { Cyclosporine }\end{array}$

\section{Introduction}

Mycophenolate mofetil (MMF) is currently the most prescribed immunosuppressive agent in renal transplant recipients to prevent graft rejection [1]. After oral administration the prodrug $\mathrm{MMF}$ is rapidly hydrolyzed to the active agent mycophenolic acid (MPA). The majority of MPA is metabolized to the inactive 
7-O-mycophenolic acid glucuronide (MPAG), which exhibits enterohepatic recirculation (EHC). MPA is a selective, reversible inhibitor of inosine monophosphate dehydrogenase (IMPDH). IMPDH has an important role in the de novo purine synthesis in $\mathrm{T}$ and $\mathrm{B}$ lymphocytes [2]. Inhibition of this pathway causes immunosuppression, contributing to the prevention of graft rejection. Although introduced as a fixed-dose drug, debate has emerged with respect to the potential contribution of therapeutic drug monitoring (TDM) of MPA area under the total plasma concentration time curve $\left(\mathrm{AUC}_{0-12}\right)$ [3-6]. The target range for total MPA (tMPA) $\mathrm{AUC}_{0-12}$ in renal transplant recipients cotreated with cyclosporine is 30-60 mg h/l [7].

MPA is a highly protein bound drug, with a bound fraction of approximately $97 \%$, which binds reversibly to serum albumin $[8,9]$. The free fraction is thought to be responsible for the immunosuppressive effect of MPA [8, 9]. The main metabolite MPAG is approximately $82 \%$ protein bound [9]. Low plasma albumin concentrations and impaired renal function are associated with an increased clearance of tMPA and with a decreased $\mathrm{AUC}_{0-12}$ of tMPA [10]. The effect of impaired renal function on unbound MPA (fMPA) plasma concentrations is however not clear: some studies have reported an increase in fMPA $\mathrm{AUC}_{0-12}$ [11-15], whereas in other studies unbound exposure was unchanged [16, 17].

Coadministration of the calcineurin inhibitor cyclosporine influences MPA pharmacokinetics. In renal transplant recipients, significantly increased tMPA clearance and decreased tMPA $\mathrm{AUC}_{0-12}$ occurs with cyclosporine coadministration compared with tacrolimus coadministration $[18,19]$. This effect can be explained by reduced EHC of MPAG in case of cyclosporine cotreatment due to inhibition of the multi-drug resistance-associated protein 2 (MRP2) enzyme [20].

Decreased tMPA exposure correlates with a higher risk for acute rejection [21-23], whereas an increase in unbound MPA exposure may produce hematological toxicity and infections $[23,24]$. On the basis of these data it is unclear whether a decreased total MPA $\mathrm{AUC}_{0-12}$, caused by impaired renal function or low albumin concentrations, should be corrected with an increase in MMF dose, as the patient subsequently may be at risk for adverse events.

The aim of this study was to develop a population pharmacokinetic model, which describes the relationship between MMF dose and both total and unbound plasma concentrations of MPA and MPAG. Using this model, it will be investigated how renal function, plasma albumin and cotreatment with cyclosporine influence the pharmacokinetics of tMPA and fMPA. The developed model may provide insight in the necessity to adjust the MMF dose in situations of impaired renal function and low albumin concentrations.

\section{Methods}

\section{Patients}

Pharmacokinetic data from two previously performed studies were used for the current analysis. In the first trial, a randomized concentration controlled trial 
(RCCT) [25], de novo renal transplant recipients were divided into three MPA AUC target groups. All patients in this study were cotreated with cyclosporine and corticosteroids as concomitant immunosuppressive therapy. In this study, tMPA, fMPA and total MPAG (tMPAG) concentrations were measured at day 3, 7, 11, 21, 28, 56, 84, 112 and 140 after transplantation. On days 3, 7 and 11 posttransplantation, sample times were predose and $0.33,0.66,1.25,2,6,8$ and $12 \mathrm{~h}$ after oral intake of MMF. On the remaining occasions, sample times were predose and 0.33 , $0.66,1.25$ and $2 \mathrm{~h}$ postdose. Concentrations were measured using a validated highperformance liquid chromatography (HPLC) method [26]. MMF dose was adjusted based on these measurements. From a subset of 88 patients fMPA concentrations were measured on one or two of the nine occasions, which were nominally day 11 and/or day 140. These fMPA concentrations were analyzed using a validated ultrafiltration procedure [27].

In the second trial, the IMPDH-activity study [28], de novo renal transplant recipients started with $1000 \mathrm{mg}$ MMF twice daily, combined with tacrolimus and corticosteroids. MMF dose was adjusted based on clinical evaluations. In the IMPDH-activity study tMPA, fMPA, tMPAG and unbound MPAG (fMPAG) concentrations were measured at day 6,21, 49 and 140 after transplantation. On day 6 , samples were taken predose and $0.5,1,2,6$ and $12 \mathrm{~h}$ postdose. On the remaining occasions, sample times were predose and 0.5 and $2 \mathrm{~h}$ after oral intake of MMF. Concentrations were measured using a validated liquid chromatography-tandem mass spectrometry (LC-MS/MS) method [29]. For the determination of unbound plasma concentrations of MPA and MPAG, plasma was ultrafiltrated first. A detailed description of these studies was published previously [25, 28].

\section{Pharmacokinetic analysis}

\section{Basic model}

The MMF dose and analysed MPA and MPAG concentrations were converted to molar equivalents by dividing them by their molecular weight (MMF $433.5 \mathrm{~g} / \mathrm{mol}$; MPA $320.3 \mathrm{~g} / \mathrm{mol}$; MPAG $496.5 \mathrm{~g} / \mathrm{mol}$ ). The data of both studies were simultaneously fitted using the nonlinear mixed-effect modeling software program NONMEM (version VI, level 2.0; Globomax LLC, Ellicott City, MD, USA). The first-order (FO) method was used throughout to fit the logarithmically transformed concentration-time data, because of the high computational intensity of the first order conditional estimate method.

The minimum value of objective function (OFV) was used as a criterion for model selection. If the difference between two nested models was larger than the critical value from a $\mathrm{X}^{2}$ distribution with degrees of freedom equal to the difference in the number of estimated parameters, the models were significantly different from each other. A decrease in OFV $>10.83$ showed a significant improvement of a nested model with one degree of freedom of $P<0.001$. Model adequacy was further evaluated by using various residual plots ("goodness-of-fit" plots) and values of random effects variances. To assess the graphical goodness of fit, 
extensive plotting was available via Xpose [30], a purpose built set of subroutines in S-plus (version 6.1; Insightful Corp, Seattle, WA, USA).

A compartmental pharmacokinetic model was developed for fMPA and IMPAG. Several structural models were tested. Models with 1 or 2 compartments were evaluated, as well as models with and without absorption lag-time $\left(\mathrm{T}_{\mathrm{LAG}}\right)$. Furthermore, it was evaluated whether absorption was best described as a zero-order or first-order process. Pharmacokinetic parameters were estimated in terms of central and peripheral volume of distribution (V), clearance (CL), and intercompartmental clearance $(\mathrm{Q})$. Because bioavailability $(\mathrm{F})$ could not be quantified, V, CL and $\mathrm{Q}$ values correspond to the ratios $\mathrm{V} / \mathrm{F}, \mathrm{CL} / \mathrm{F}$, and $\mathrm{Q} / \mathrm{F}$. Addition of interpatient variability (IPV), described using an exponential error model, was evaluated for each pharmacokinetic parameter. The covariance between values for IPV was estimated using a variance-covariance matrix. Residual variability between observed and predicted MPA plasma concentrations was described using an additional error model for logarithmically transformed data.

Protein bound MPA (bMPA) and bound MPAG (bMPAG) were described by addition of a protein binding compartment, containing a maximum number of binding sites $\left(\mathrm{B}_{\max }\right)$ at which MPA and MPAG could bind (Fig. 1). In this model MPA and MPAG were allowed to bind competitively with the protein binding sites, and replace each other from these binding sites as described by

$$
\begin{gathered}
\frac{\mathrm{dA}_{1}}{d t}=-k_{a} \cdot A_{1} \\
\frac{\mathrm{dA}_{2}}{d t}=k_{a} \cdot A_{1}-\mathrm{k}_{25} \cdot A_{2}-\mathrm{k}_{23} \cdot A_{2}+\mathrm{k}_{32} \cdot A_{3} \\
-\mathrm{k}_{24} \cdot A_{2} \cdot\left(B_{M A X}-\mathrm{A}_{4}-\mathrm{A}_{6}\right)+k_{24} \cdot A_{4}+k_{72} \cdot A_{7} \\
\frac{\mathrm{dA}_{3}}{d t}=k_{23} \cdot A_{2}-\mathrm{k}_{32} \cdot A_{3} \\
\frac{\mathrm{dA}_{4}}{d t}=k_{24} \cdot A_{2} \cdot\left(B_{M A X}-\mathrm{A}_{4}-\mathrm{A}_{6}\right)-\mathrm{k}_{42} \cdot A_{4} \\
\frac{\mathrm{dA}}{d t}=k_{25} \cdot A_{2}-\mathrm{k}_{56} \cdot A_{5} \cdot\left(B_{M A X}-\mathrm{A}_{4}-\mathrm{A}_{6}\right) \\
+k_{65} \cdot A_{6}-k_{50} \cdot A_{5}-\mathrm{k}_{57} \cdot A_{5} \\
\frac{\mathrm{dA}_{6}}{d t}=k_{56} \cdot A_{5} \cdot\left(B_{M A X}-\mathrm{A}_{4}-\mathrm{A}_{6}\right)-\mathrm{k}_{65} \cdot A_{6} \\
\frac{\mathrm{dA} 7}{d t}=k_{57} \cdot A_{5}-\mathrm{k}_{72} \cdot A_{7},
\end{gathered}
$$

where $A_{n}$ represents the amount of a substance in the $n$th compartment and $k_{n m}$ represents the rate constant for transport between compartment $\mathrm{n}$ and compartment $\mathrm{m}$. Values for the dissociation constant $\left(\mathrm{K}_{\mathrm{D}}\right)$ can be calculated from this differential equations by dividing $\mathrm{k}_{42}$ by $\mathrm{k}_{24}$ for MPA and $\mathrm{k}_{65}$ by $\mathrm{k}_{56}$ for MPAG. The concentrations of tMPA and tMPAG were modeled as the sum of the unbound and bound concentrations. 


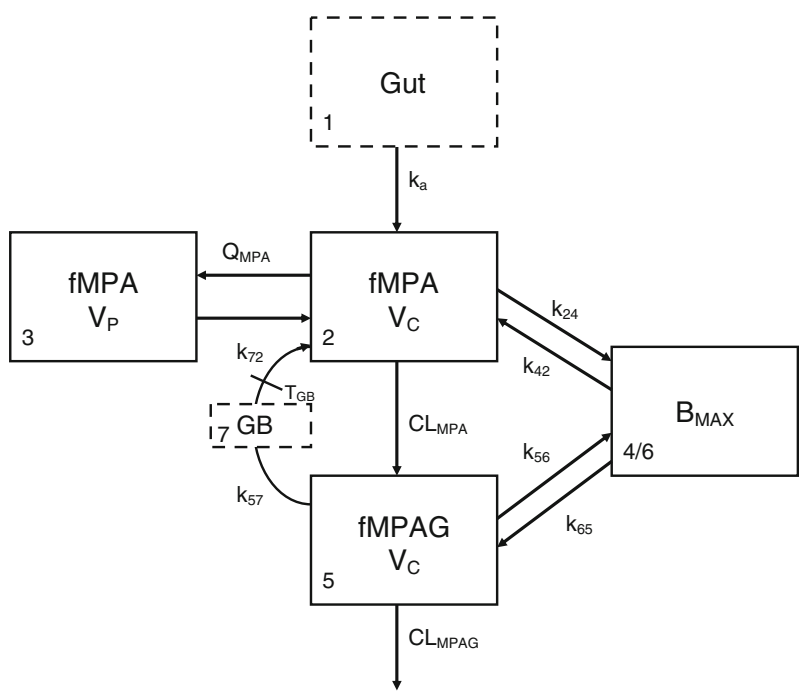

Fig. 1 Graphical representation of the final model. MPA and MPAG bind competitively to the protein binding sites. fMPA is cleared to fMPAG by first order elimination. fMPAG is eliminated by a first order process $\left(\mathrm{CL}_{\mathrm{MPAG}}\right)$, or undergoes enterohepatic recirculation via the gall bladder compartment

Furthermore, to describe the EHC of the drug a gallbladder compartment was added, which is responsible for the reconversion of fMPAG into fMPA (Fig. 1). It was evaluated whether transport of fMPAG to the gallbladder was best described as a zero-order or first-order process. The gallbladder emptied into the central compartment of fMPA at a certain time point postdose [31].

\section{Covariate model}

Finally, to explain IPV, relationships were investigated between pharmacokinetic parameters and patient characteristics known to influence MPA pharmacokinetics. Covariates assessed were renal function, plasma albumin concentration, and cyclosporine comedication. Renal function was tested by calculation of the creatinine clearance (CrCL) according to Cockcroft and Gault [32]. Continuous covariates, such as albumin concentration (Alb) were modeled by using an exponential model, as shown in Eq. 8.

$$
\theta_{i}=\theta_{\text {pop }} \cdot(A l b / 0.5)^{\theta_{a l b}}
$$

where $\theta_{i}$ represents the parameter for ith individual, $\theta_{\text {pop }}$ is the population value with $\mathrm{Alb}=0.5 \mathrm{mmol} / \mathrm{l}$, and $\theta_{\text {alb }}$ is an exponent determining the shape of the correlation. Categorical variables, such as cyclosporine comedication, were modeled proportionally as shown in Eq. 9. 


$$
\theta_{i}=\theta_{p o p} \cdot \theta_{C s A}^{C s A}
$$

where $\mathrm{CsA}=1$ for patients cotreated with cyclosporine and $\mathrm{CsA}=0$ for patients not cotreated with cyclosporine, and $\theta_{C s A}$ represents the fractional change of the parameter in patients cotreated with cyclosporine.

\section{Model validation}

The final model was validated by a visual predictive check [33]. Data sets $(n=50)$ were simulated from the original data set using the final model. Per time point, the dose-corrected median simulated concentrations plus 95-percentile intervals were compared graphically with the observed concentrations for fMPA, tMPA, fMPAG, and tMPAG separately. The dataset was analyzed separately for different categories of the covariates included in the final model.

\section{Simulation study}

The final model was used to examine the impact of changes in covariates on the pharmacokinetics of MPA and MPAG. Simulations were performed to demonstrate how the disposition of MPA and MPAG was affected by clinically relevant changes in renal function, plasma albumin concentration and cyclosporine comedication. Simulations were performed with the final model for 50 patients treated with $1 \mathrm{~g}$ MMF twice daily and cyclosporine, and for 50 patients treated with $1 \mathrm{~g}$ MMF twice daily and tacrolimus. CrCL was initially set on $50 \mathrm{ml} / \mathrm{min}$, and was decreased to 30 and $10 \mathrm{ml} / \mathrm{min}$. The initial value for albumin concentration was $0.5 \mathrm{mmol} / \mathrm{l}$, which was varied to 0.4 and $0.6 \mathrm{mmol} / \mathrm{l}$. Changes in concentration-time profiles, free fraction and $\mathrm{AUC}_{0-12}$ values of fMPA, tMPA, fMPAG and tMPAG were assessed.

\section{Results}

\section{Patients}

The data set contained 489 tMPA, 489 fMPA, 488 tMPAG, and 210 fMPAG plasma concentrations obtained from 75 patients cotreated with cyclosporine or tacrolimus. Each patient participated in one or two pharmacokinetic assessments at different time points after transplantation. In total, 93 concentration-time profiles were used for the analysis. Patient characteristics are described in Table 1.

Pharmacokinetic analysis

\section{Compartmental model with protein binding}

The final model is shown in Fig. 1, corresponding typical population pharmacokinetic estimates are summarized in Table 2. The standard errors of the estimated parameters could not be obtained due to rounding errors of the final run. The 
Table 1 Patient characteristics

\begin{tabular}{|c|c|c|}
\hline Cotreatment & $\begin{array}{l}\text { Cyclosporine } \\
(n=48 \text { profiles })\end{array}$ & $\begin{array}{l}\text { Tacrolimus } \\
(n=45 \text { profiles })\end{array}$ \\
\hline Gender (male/female) ${ }^{\mathrm{a}}$ & $30 / 17$ & $18 / 10$ \\
\hline Age (years) ${ }^{\mathrm{a}}$ & $51(21-70)$ & $53(19-76)$ \\
\hline Weight $(\mathrm{kg})^{\mathrm{a}}$ & 67 (42-99) & $78(44-113)$ \\
\hline Number of patients with $\mathrm{DGF}^{\mathrm{a}}$ & 4 & 11 \\
\hline Number of diabetic patients pretransplantation ${ }^{a}$ & 2 & 2 \\
\hline Time after transplantation (days) & $11(7-155)$ & $11(4-115)$ \\
\hline Plasma albumin $(\mathrm{mmol} / \mathrm{l})$ & $0.51(0.38-0.61)$ & $0.51(0.35-0.68)$ \\
\hline Creatinine clearance $(\mathrm{ml} / \mathrm{min})^{\mathrm{b}}$ & $44(8-107)$ & $45(8-154)$ \\
\hline Heamoglobine (mmol Fe/l) & $9.6(6.9-13.0)$ & $8.0(4.2-13.0)$ \\
\hline ASAT (U/1) & $15(6-50)$ & $19(6-236)$ \\
\hline ALAT (U/1) & $20(7-155)$ & $27(7-534)$ \\
\hline MMF dose (mg bid) & $1350(400-2200)$ & $1000(500-1500)$ \\
\hline CNI daily dose (mg) & $512.5(250-1125)$ & $8(1-20)$ \\
\hline CNI predose concentration $(\mu \mathrm{g} / \mathrm{l})$ & $267.5(21.0-619.1)$ & $10.0(1.5-30.0)$ \\
\hline
\end{tabular}

Parameters are presented as median (range) of all profiles, for patients treated with the calcineurin inhibitors $(C N I)$ cyclosporine and tacrolimus. DGF delayed graft function, ASAT aspartate aminotransferase, ALAT alanine transaminase, $M M F$ mycophenolate mofetil

a parameters for all patients, of which some participated in two pharmacokinetic assessments

b calculated with Cockcroft \& Gault-formula

pharmacokinetics of fMPA were described with a two-compartment model, containing a central- and peripheral volume of distribution. fMPA from the central compartment bound to the protein binding sites. The number of binding sites $\left(\mathrm{B}_{\mathrm{MAX}}\right)$ was limited, which resulted in a saturable binding process. The pharmacokinetics of fMPAG were modeled with one, central compartment. From this compartment, fMPAG bound to the same binding sites as IMPA, which resulted in competitive binding. Due to this competition MPA and MPAG were able to displace each other from the protein binding sites. Inclusion of the competitive binding between MPA and MPAG significantly improved the model compared to the model without competition $(\triangle \mathrm{OFV}=-37)$. The protein binding and unbinding rate constants of fMPA $\left(\mathrm{k}_{24}\right.$ and $\left.\mathrm{k}_{42}\right)$ and fMPAG $\left(\mathrm{k}_{56}\right.$ and $\left.\mathrm{k}_{65}\right)$ provide information on the affinity of both substances to the protein binding sites, which is higher for fMPA $\left(\mathrm{K}_{\mathrm{D}}=1100 \mu \mathrm{mol}\right)$ than for fMPAG $\left(\mathrm{K}_{\mathrm{D}}=7000 \mu \mathrm{mol}\right)$. The interpatient variability (IPV) in protein binding was described for $\mathrm{B}_{\mathrm{MAX}}$ using an exponential error model.

\section{Enterohepatic recirculation}

The EHC was modeled by using a gallbladder compartment (Fig. 1, compartment 7). Transport of fMPAG from the central compartment to the gallbladder compartment was characterized using the first order rate constant $\mathrm{k}_{57}$. Emptying 
Table 2 Parameter estimates of the pharmacokinetic model

\begin{tabular}{|c|c|c|c|}
\hline \multirow{26}{*}{$\begin{array}{l}\text { Table } 2 \text { Parameter estimates of } \\
\text { the pharmacokinetic model }\end{array}$} & Parameter & Value & $\operatorname{IPV}(\%)$ \\
\hline & $\mathrm{T}_{\mathrm{LAG}}(\mathrm{h})$ & 0.231 & 161 \\
\hline & $\mathrm{k}_{\mathrm{a}}\left(\mathrm{h}^{-1}\right)$ & $4.00^{\mathrm{a}}$ & \\
\hline & $\mathrm{V}_{\mathrm{c}} \mathrm{fMPA}(1)$ & 189 & 116 \\
\hline & CL fMPA (1/h) & 747 & 97 \\
\hline & $\mathrm{V}_{\mathrm{p}}$ fMPA $(1)$ & 34300 & \\
\hline & Q fMPA $(1 / h)$ & 2010 & \\
\hline & $\mathrm{k}_{24}\left(\mathrm{~h}^{-1} \mu \mathrm{mol}^{-1}\right)$ & 0.153 & \\
\hline & $\mathrm{B}_{\mathrm{MAX}}(\mu \mathrm{mol})$ & 35100 & 48 \\
\hline & $\mathrm{k}_{42}\left(\mathrm{~h}^{-1}\right)$ & 169 & \\
\hline & $\mathrm{V}_{\mathrm{c}}$ fMPAG $(1)$ & 8.56 & \\
\hline & $\mathrm{k}_{56}\left(\mathrm{~h}^{-1} \mu \mathrm{mol}^{-1}\right)$ & 0.0133 & \\
\hline & $\mathrm{k}_{65}\left(\mathrm{~h}^{-1}\right)$ & 93.1 & \\
\hline & CL fMPAG $(1 / h)$ & 4.75 & 106 \\
\hline & $\mathrm{T}_{\mathrm{GB}}(\mathrm{h})$ & 7.90 & $141^{\mathrm{a}}$ \\
\hline & $\mathrm{D}_{\mathrm{GB}}(\mathrm{h})$ & $1.00^{\mathrm{a}}$ & \\
\hline & $\mathrm{k}_{72}\left(\mathrm{~h}^{-1}\right)$ & $10.0^{\mathrm{a}}$ & \\
\hline & $\mathrm{k}_{57}\left(\mathrm{~h}^{-1}\right)$ & 0.0796 & $71^{\mathrm{a}}$ \\
\hline & Residual variability & & \\
\hline & Additive error tMPA (mmol/l) & 0.52 & \\
\hline & Additive error fMPA (mmol/l) & 0.993 & \\
\hline & Additive error tMPAG (mmol/l) & 0.186 & \\
\hline & Additive error fMPAG (mmol/l) & 0.551 & \\
\hline & Covariate effects & & \\
\hline & CrCL on CL fMPAG & 1.36 & \\
\hline & Albumine on $\mathrm{B}_{\mathrm{MAX}}$ & 1.39 & \\
\hline The parameter is fixed at this & CsA on $\mathrm{k}_{57}$ & 0.002 & \\
\hline
\end{tabular}

of the gallbladder into the central compartment of fMPA occurred at a certain time point $\left(\mathrm{T}_{\mathrm{GB}}\right)$ with rate constant $\mathrm{k}_{72}$ and duration $\mathrm{D}_{\mathrm{GB}}$. Unfortunately, insufficient data were collected between 4 and $10 \mathrm{~h}$ postdose, the period at which the gallbladder is expected to empty. As a result, the parameters describing the gallbladder emptying, $\mathrm{D}_{\mathrm{GB}}$ and $\mathrm{k}_{72}$, were fixed at $1 \mathrm{~h}$ and $10 \mathrm{~h}^{-1}$. IPV was described with an additional error model for $\mathrm{T}_{\mathrm{GB}}$ and with an exponential error model for $\mathrm{k}_{57}$. However, the IPV of $\mathrm{k}_{57}$ had to be fixed at $71 \%$, to prevent variability on EHC to take on extreme values. This value was based on the variance in EHC from 10 to $60 \%$ as described in literature [9]. In comparison with a model without EHC $\left(\mathrm{k}_{57}=0 \mathrm{~h}^{-1}\right)$, addition of the EHC significantly improved the model $(\triangle \mathrm{OFV}=-43)$.

\section{Covariate analysis}

Decreased plasma albumin concentrations are known to be associated with reduced protein binding of MPA [34]. Inclusion of plasma albumin concentration as 
covariate of $\mathrm{B}_{\mathrm{MAX}}$ (Eq. 3) significantly improved the model $(\Delta \mathrm{OFV}=-26)$. The IPV of fMPA CL, fMPAG CL and $\mathrm{B}_{\text {MAX }}$ decreased slightly with 1,6 and $1 \%$, respectively. A decrease in albumin from 0.6 to $0.4 \mathrm{mmol} / \mathrm{l}$ resulted in a decrease in the number of binding sites from 45200 to $25700 \mu \mathrm{mol}$, as is graphically shown in Fig. 2a.

Impaired renal function reduced renal clearance of MPAG [35]. In the present study, a significant correlation was observed between CrCL and fMPAG CL. Introduction of CrCL improved the goodness of the fit $(\triangle \mathrm{OFV}=-48)$. The IPV of fMPA CL, fMPAG CL and $\mathrm{B}_{\mathrm{MAX}}$ decreased with 25,57 and $17 \%$, respectively. A decrease in CrCL from 45 to $25 \mathrm{ml} / \mathrm{min}$ resulted in a decrease from 4.75 to $2.14 \mathrm{l} / \mathrm{h}$ in clearance of fMPAG (Fig. 2b). No correlation was seen between CrCL and fMPA CL.

Cyclosporine decreases the EHC of MPAG by inhibition of MRP2 [20]. In the present study, implementation of cyclosporine as covariate on $\mathrm{k}_{57}$ significantly improved the model $(\Delta \mathrm{OFV}=-17)$. In patients cotreated with cyclosporine $\mathrm{k}_{56}$ is very small with a value of $0.000159 \mathrm{~h}^{-1}$ compared to $0.0796 \mathrm{~h}^{-1}$ in patients cotreated with tacrolimus. Inclusion of cyclosporine as a covariate on fMPA clearance did not significantly improve the model further.

\section{Evaluation of the final model}

The goodness-of-fit plots (Fig. 3) of the final model were evaluated for tMPA, fMPA, tMPAG and fMPAG separately. The scatter plots of predicted and individually predicted versus observed concentrations showed no structural bias, except for a small underprediction of the maximum concentration of tMPA and fMPA. The weighted residuals exhibited a homogeneous distribution over the whole sampling period (data not shown).

A

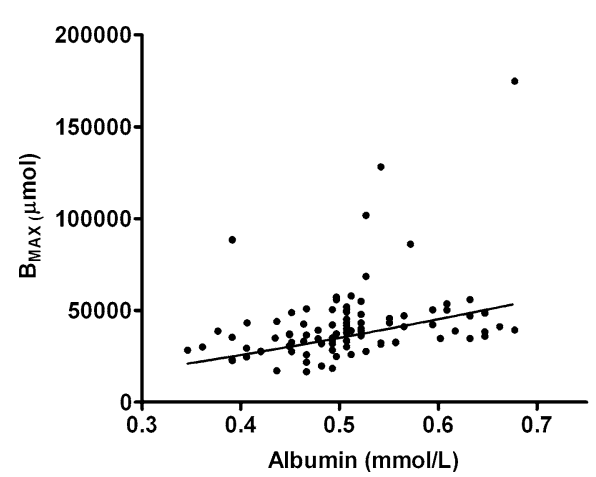

B

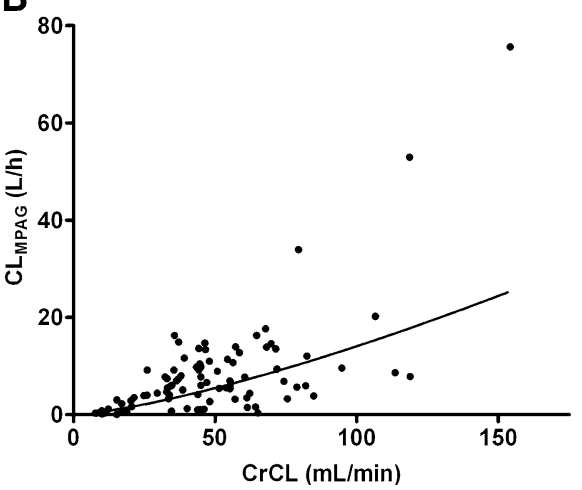

Fig. 2 Correlation of pharmacokinetic parameters versus covariate effects for a the number of protein binding sites $\left(\mathrm{B}_{\mathrm{MAX}}\right)$ and plasma albumin concentration, and b fMPAG clearance and creatinine clearance $(\mathrm{CrCL})$. The line represents the estimated correlation between the pharmacokinetic parameter and the covariate 
Figure 4 shows the results of the visual predictive check for the final model. The results are presented separately for patients cotreated with cyclosporine and tacrolimus. Good agreement between the simulated and observed concentrations was apparent at all sampling time points. However, there seemed to be a small underprediction of the maximum tMPA and fMPA concentration. The visual predictive check was performed separately for patients with $\mathrm{CrCL}<30 \mathrm{ml} / \mathrm{min}$, CrCL 30-50 ml/min and $\mathrm{CrCL}>50 \mathrm{ml} / \mathrm{min}$ as well as for patients with albumin concentrations $<0.5$ and $>0.5 \mathrm{mmol} / \mathrm{l}$. The results of these visual predictive checks on these selections gave similar results (data not shown).

\section{Simulations}

The pharmacokinetic profiles of tMPA, fMPA, tMPAG and fMPAG were simulated for 50 renal transplant recipients receiving $1 \mathrm{~g}$ MMF twice daily using the final model. Covariate effects were set at typical values: plasma albumin concentration $0.5 \mathrm{mmol} / \mathrm{l}, \mathrm{CrCL} 50 \mathrm{ml} / \mathrm{min}$ and comedication was cyclosporine or tacrolimus. Subsequently, the effect of a change in plasma albumin concentration or CrCL was evaluated.

A decrease in plasma albumin concentrations from 0.6 to $0.4 \mathrm{mmol} / 1$, resulted in decreased tMPA concentrations, whereas the effect on AMPA, tMPAG and AMPAG concentrations was small (Fig. 5). The free fraction of both, MPA and MPAG, almost doubled when albumin concentrations decreased from 0.6 to $0.4 \mathrm{mmol} / \mathrm{l}$ (Fig. 6). This effect was larger for patients cotreated with cyclosporine (MPA: 2.4-5.3\%, MPAG: 13.7-26.1\%) than for patients cotreated with tacrolimus (MPA: 2.7-4.1\%, MPAG: 14.9-21.3\%). Furthermore, tMPA $\mathrm{AUC}_{0-12}$ values were decreased in patients with low albumin concentrations (Fig. 7). A decrease in albumin concentrations from 0.6 to $0.4 \mathrm{mmol} / \mathrm{l}$, resulted in a decrease in mean tMPA AUC from 30.1 to $17.7 \mathrm{mg} \mathrm{h} / \mathrm{l}$ in patients cotreated with cyclosporine and from 31.1 to $20.4 \mathrm{mg} \mathrm{h} / \mathrm{l}$ in patients cotreated with tacrolimus. Consequently, a decrease in albumin concentrations may cause a major underexposure to tMPA, as the lower limit of the therapeutic window of tMPA AUC is $30 \mathrm{mg} \mathrm{h} / \mathrm{l}$. The exposure to fMPA, tMPAG and fMPAG remained however stable, as indicated by Fig. 7b-d.

A decrease in renal function, characterized by a change in CrCL from 50 to $10 \mathrm{ml} / \mathrm{min}$, had a large impact on the MPAG concentrations (Fig. 8). Both, tMPAG and fMPAG concentrations increased, especially in patients cotreated with cyclosporine. The changes in the concentration-time profiles of tMPA and IMPA were small. A slight difference was seen at the end of the curve, where the tacrolimus cotreated patients showed a higher EHC with impaired renal function (Fig. 8e-f). This was caused by increased concentrations of fMPAG. The latter undergoes EHC and is subsequently converted to MPA. tMPAG and fMPAG AUC values were higher in patients with impaired renal function (Fig. 9). Corresponding AUC values for tMPAG increased from 831 to $3794 \mathrm{mg} \mathrm{h} / 1$ for patients cotreated with cyclosporine and from 723 to $2647 \mathrm{mg} \mathrm{h} / \mathrm{l}$ in patients with tacrolimus as comedication. A decrease in CrCL from 50 to $10 \mathrm{ml} / \mathrm{min}$ resulted in increased tMPA AUC in patients treated with tacrolimus (25.1-31.6 mg h/l). The opposite effect was seen in patients treated with cyclosporine, in which tMPA AUC values 

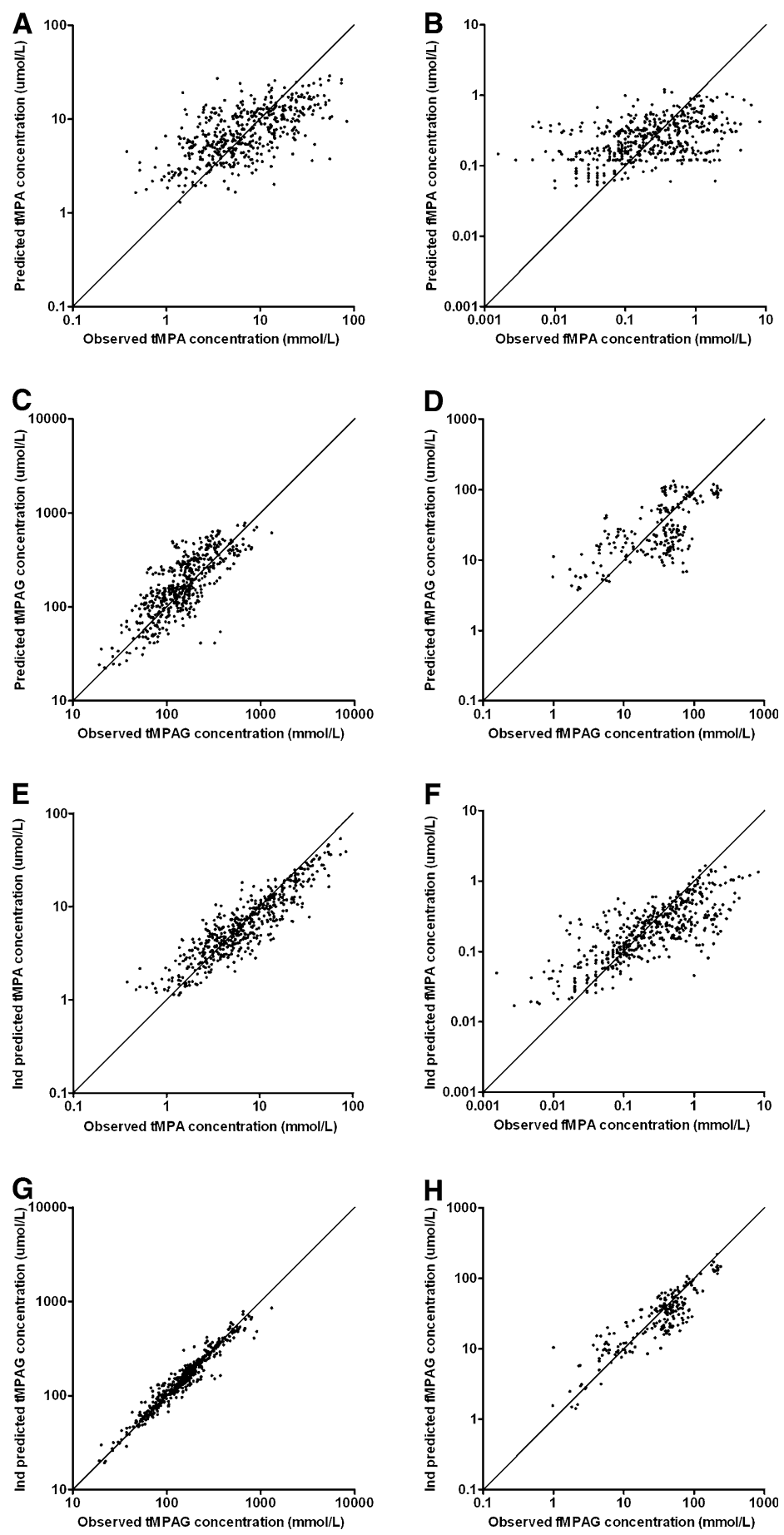
Fig. 3 Goodness-of-fit plots of observed versus population predicted concentrations of a tMPA, b fMPA, c tMPAG and d fMPAG, and observed versus individually predicted concentrations of e tMPA, f fMPA, $\mathbf{g}$ tMPAG and $\mathbf{h}$ fMPAG. In the plots the line of identity is presented

decreased from 23.9 to $21.5 \mathrm{mg} \mathrm{h} / \mathrm{l}$. Furthermore, fMPA AUC values remained stable when renal function decreased, except for a small increase in fMPA AUC in patients with $\mathrm{CrCL}$ of $10 \mathrm{ml} / \mathrm{min}$ and tacrolimus as comedication. The free fraction of both MPA and MPAG increased in patients treated with cyclosporine (Fig. 10). In tacrolimus treated patients no difference in free fraction was seen.

\section{Discussion}

A population pharmacokinetic model has been developed describing the protein binding of MPA and the main metabolite MPAG for renal transplant recipients receiving MMF and cyclosporine or tacrolimus (Fig. 1). The model provided a semi-mechanistic explanation for increase of tMPA AUC and decrease in MPA free fraction with increasing plasma albumin concentrations, renal function and tacrolimus comedication. Simulations with the final model can be used to provide information about the effect of changes in albumin concentration or renal function on tMPA and fMPA exposure.

Van Hest et al. [36] have previously published an empirical model describing the protein binding of MPA. The current model is superior compared to the model of van Hest et al. due to a more mechanism-based character of the model. Our model described the protein binding process with a mass balance, based on physiological processes. Mechanism-based models have much better properties for extrapolation and prediction than empirical models [37].

In the current model, a competitive protein binding process was incorporated, which described the interaction between MPA and MPAG. Increasing MPAG concentrations were associated with increased free fractions of MPA and decreased tMPA exposure. The model did not only describe the protein binding of MPA, but also of the main metabolite MPAG. This was possible due to availability of fMPAG concentration-time profiles, which were not available in the study of van Hest et al. [36]. This addition allowed the protein binding process to be competitive between MPA and MPAG.

Due to the complexity of the model, runtimes were very long ( $55 \mathrm{~h}$ for the final run). The final run did not minimize successfully, due to rounding errors. As a result, no standard errors of the parameter estimates were obtained. Other methods to obtain information about the accuracy of the estimated parameters, like the bootstrap resampling method and the jackknife, could not be used because of the high computational intensity. However, the visual predictive check revealed a good agreement between the simulated and observed concentrations at all sampling time points, which indicate that the estimations of the pharmacokinetic parameters are reasonable. 

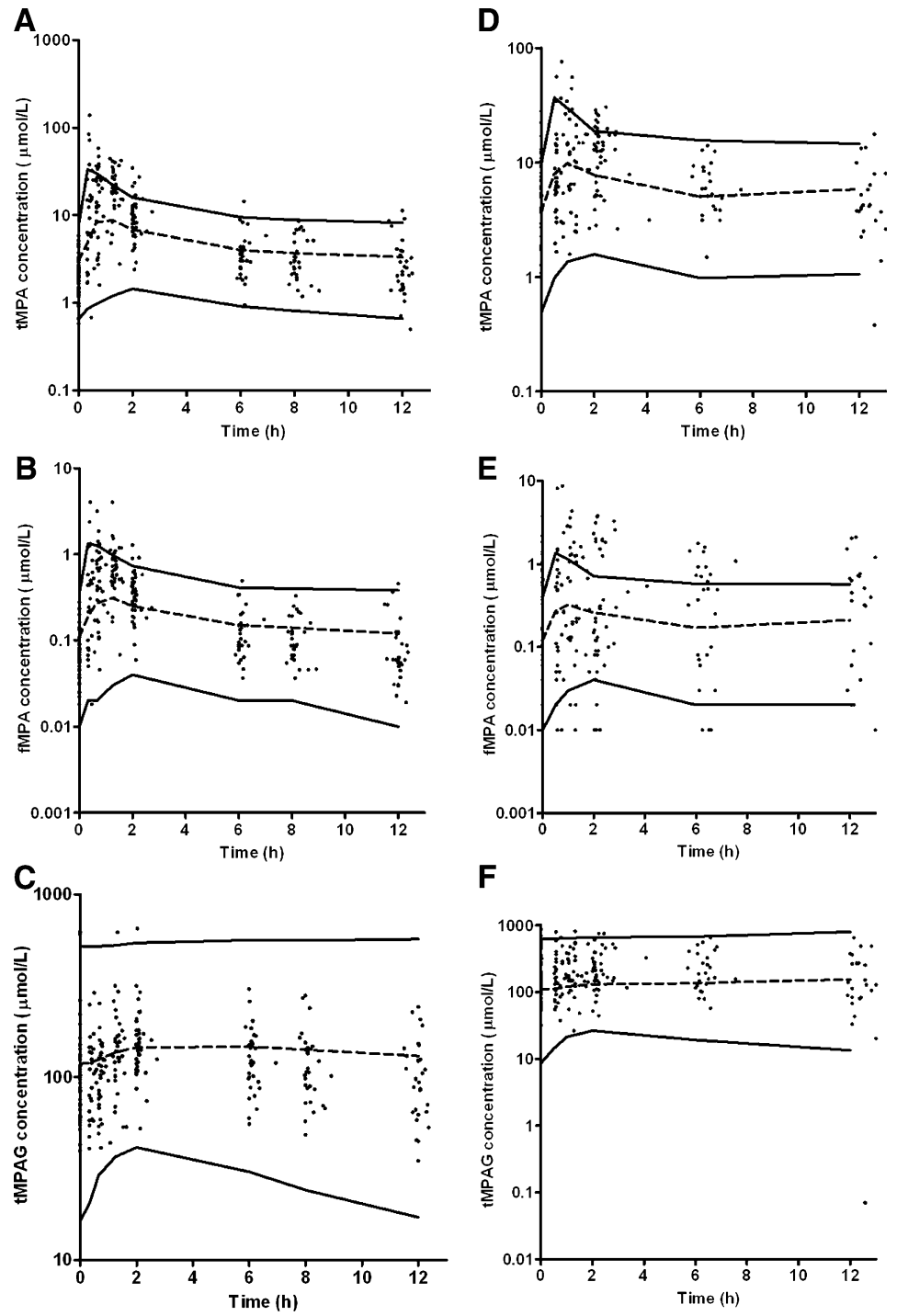

F
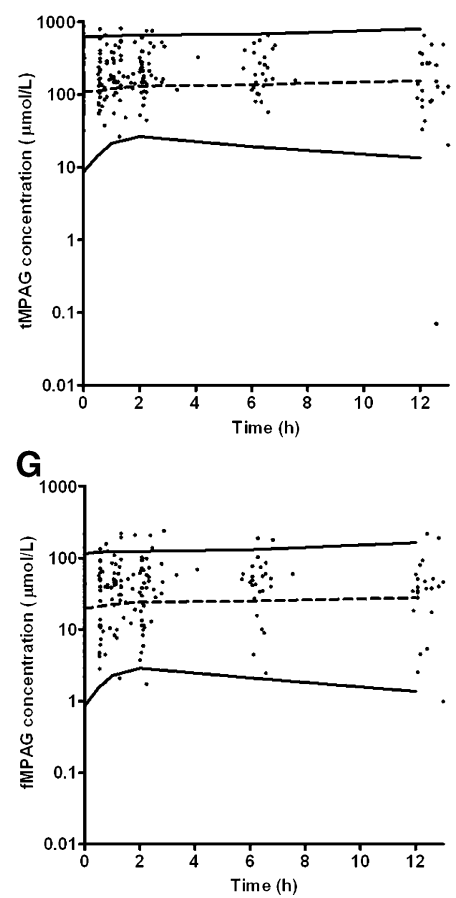
Fig. 4 Visual predictive check of the comparison of median (dashed line) with 95-percentile interval (solid lines) of 50 simulated data sets and the observed concentrations (dots). Concentrations are corrected to an MMF dose of $1 \mathrm{~g}$. Concentrations of a tMPA, b fMPA and $\mathbf{c}$ tMPAG for patients cotreated with CsA, and $\mathbf{d}$ tMPA, e fMPA, $\mathbf{f}$ tMPAG and $\mathbf{g}$ fMPAG for patients cotreated with tacrolimus

The parameter $\mathrm{B}_{\mathrm{MAX}}$ is defined as the maximum number of binding sites, to which MPA and MPAG could bind. In theory, if the volume of plasma is roughly 31 and albumin (median: $510 \mu \mathrm{mol} / \mathrm{l}$ ) has at least one binding site, then the total number of binding sites in plasma should be $\geq 510 \mu \mathrm{mol} / \mathrm{l} \times 31=1530 \mu \mathrm{mol}$. In the model, $\mathrm{B}_{\mathrm{MAX}}$ was estimated to be $35100 \mu \mathrm{mol}$, which is indeed larger than $1530 \mu \mathrm{mol}$. $\mathrm{B}_{\mathrm{MAX}}$ may be larger due to the fact that other proteins are also able to
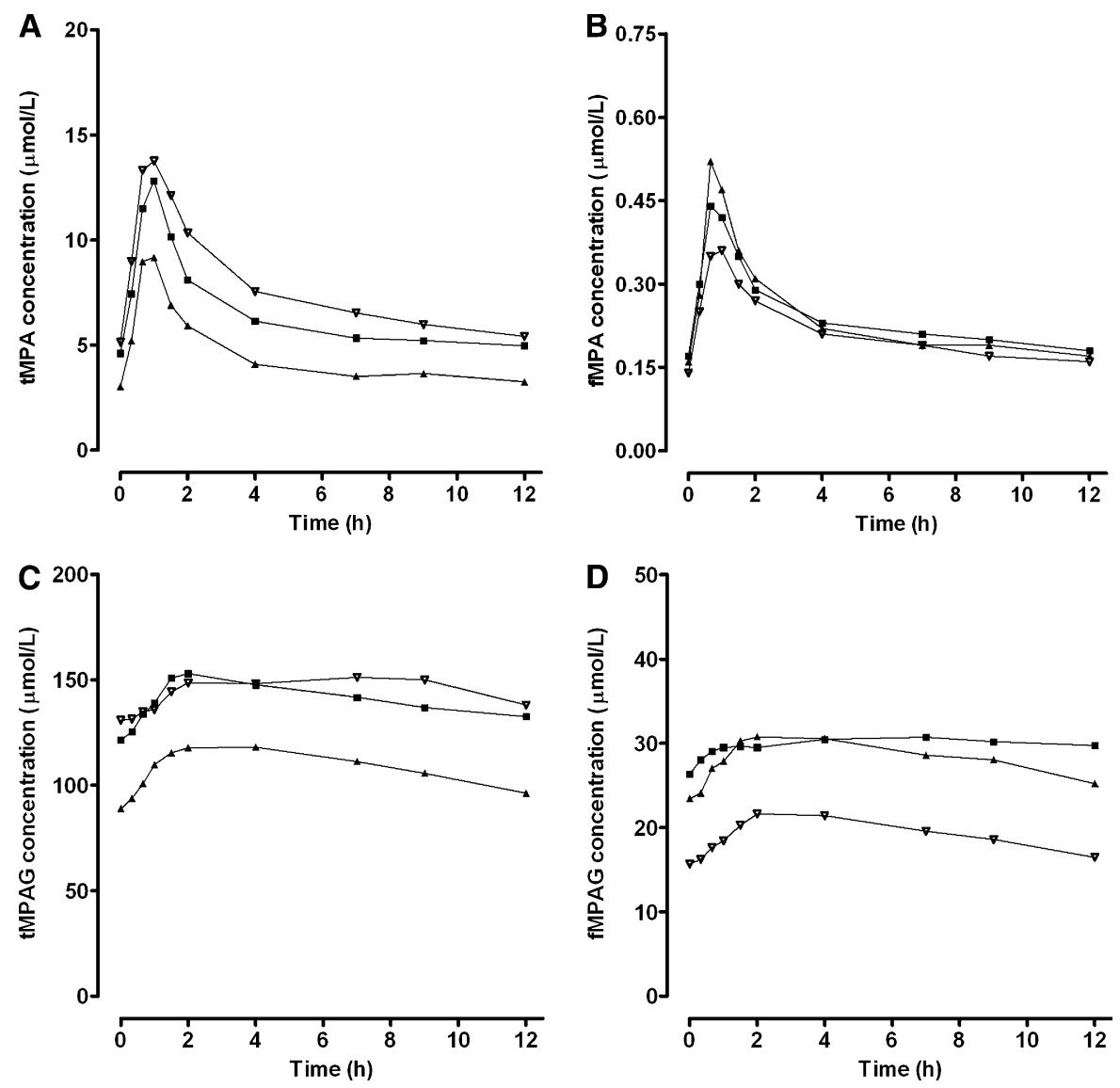

Fig. 5 Influence of albumin concentrations on pharmacokinetic profiles. Median concentration-time profiles of a tMPA, $\mathbf{b}$ fMPA, $\mathbf{c}$ tMPAG and $\mathbf{d}$ fMPAG in patients cotreated with CsA and concentrationtime profiles of e tMPA, f fMPA, $\mathbf{g}$ tMPAG and $\mathbf{h}$ fMPAG in patients cotreated with tacrolimus. Concentration-time profiles were simulated for 50 patients with albumin concentrations of (filled triangle) $0.4 \mathrm{mmol} / 1$, (filled square) $0.5 \mathrm{mmol} / 1$ and (inverted triangle) $0.6 \mathrm{mmol} / \mathrm{l}$ 

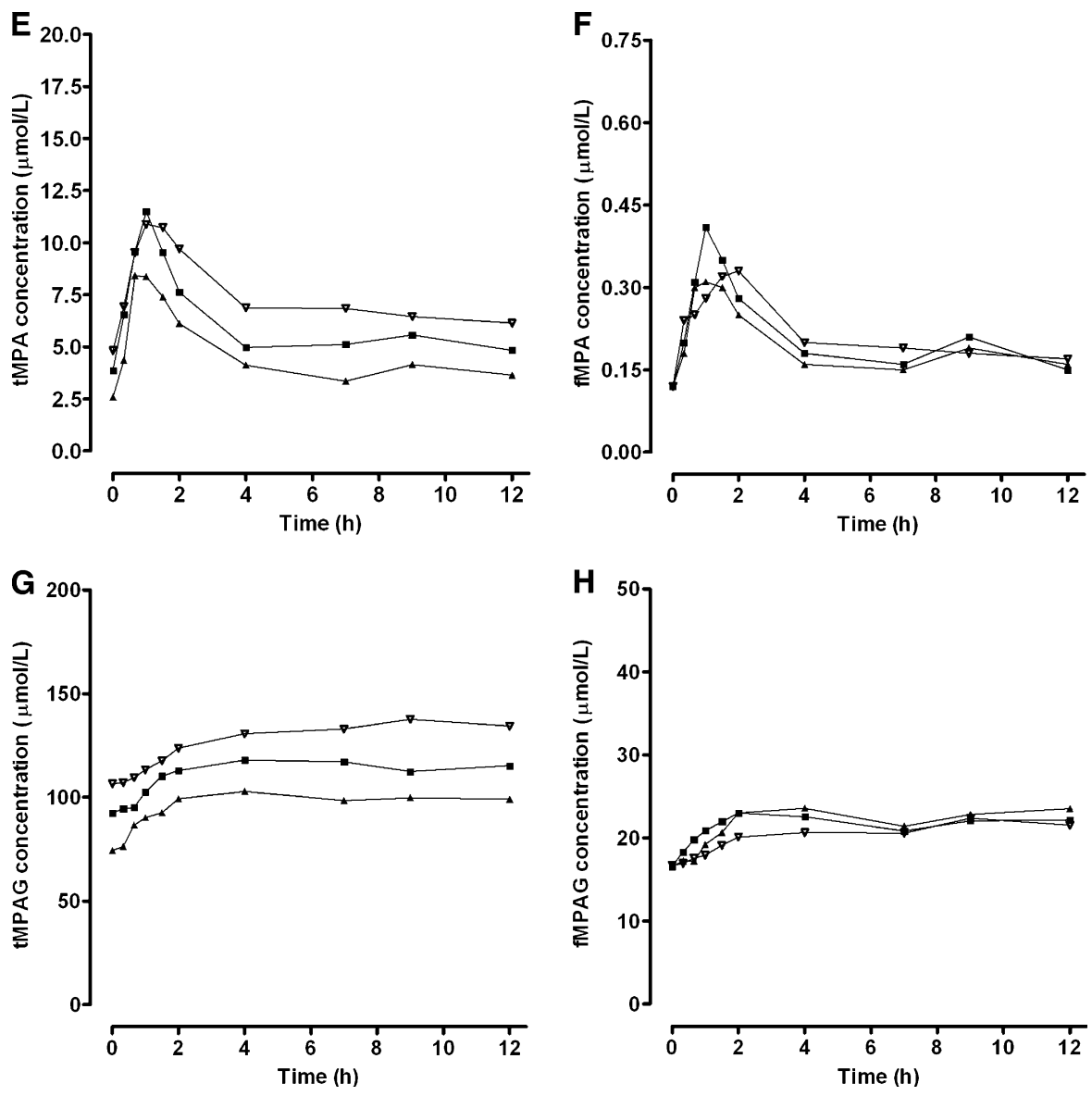

Fig. 5 continued

bind MPA or that each albumin molecule binds more than one MPA molecule. Albumin is not confined to plasma, but is continuously filtered into interstitial fluid, and then returned to plasma via the thoracic duct. Albumin-bound drugs may therefore be present in plasma, which contains $40 \%$ of albumin in the body, and in interstitial fluid, which contains the remaining 60\% [38]. The latter may increase the available number of binding sites as well.

In the model, the maximum number of binding sites available for MPA and MPAG was restricted. The number of binding sites was correlated with the plasma albumin concentration (Fig. 2a). A decrease in plasma albumin concentrations resulted in less binding sites, causing an increase in the free fraction of MPA and MPAG (Fig. 6), which has previously been reported [27, 34]. Due to this increase in the free fraction, relatively more fMPA is available for clearance, resulting in a decreased tMPA AUC (Fig. 7). However, the fMPA AUC was unaffected. The 

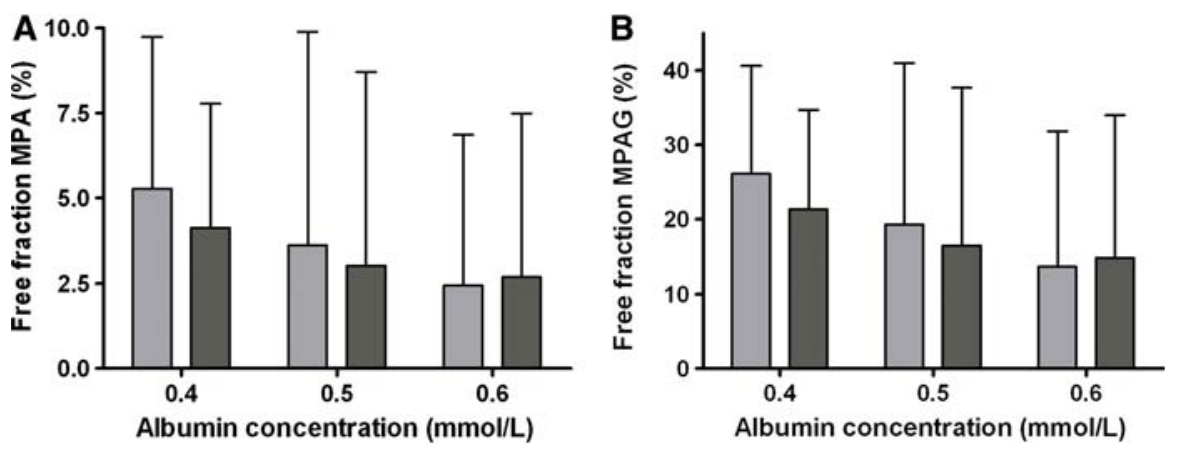

Fig. 6 Influence of albumin concentrations on the free fraction of a MPA and b MPAG. Free fractions are presented as median and 95-percentile interval of 50 simulated patients cotreated with CsA (light) or tacrolimus (dark)

phenomenon that free concentrations are independent of protein binding is characteristic for drugs with a low extraction ratio [39]. The theoretical hepatic extraction ratio of MPA is low (0.20) [40]. The simulations showed that changes in albumin concentrations cause clinically relevant changes in tMPA AUC. A decrease in albumin concentration from 0.6 to $0.4 \mathrm{mmol} / \mathrm{l}$, resulted in a decrease in tMPA AUC from 30.1 to $17.7 \mathrm{mg} \mathrm{h} / \mathrm{l}$ in patients treated with cyclosporine and from 31.1 to $20.4 \mathrm{mg} \mathrm{h} / \mathrm{l}$ in patients treated with tacrolimus. This implies that the tMPA AUC could drop below the minimal effective value of $30 \mathrm{mg} \mathrm{h} / \mathrm{l}$ and that the MMF dose should be increased. This correlation between tMPA AUC and albumin concentrations is previously seen [34, 41]. In contrast, the fMPA AUC is almost unaffected by the change in albumin concentration. A decrease in albumin concentration from 0.6 to $0.4 \mathrm{mmol} / \mathrm{l}$ resulted in an increase in fMPA AUC from 0.82 to $0.96 \mathrm{mg} \mathrm{h} / \mathrm{l}$ for patients cotreated with cyclosporine and from 0.84 to $0.93 \mathrm{mg} \mathrm{h} / \mathrm{l}$ in patients cotreated with tacrolimus.

The simulations showed that changes in CrCL have major effects on both tMPAG and fMPAG exposure, but the effects on tMPA and IMPA exposure are smaller. The CNI used in patients with impaired renal function leads to a differential effect on tMPA and fMPA exposure. In case of cyclosporine, tMPA AUC decreased and fMPA AUC remains the same. While in patients cotreated with tacrolimus, an increased exposure to tMPA and a small increase in fMPA AUC was seen when CrCL decreased to $10 \mathrm{ml} / \mathrm{min}$. These opposing effects can be explained as follows: In patients cotreated with tacrolimus, impaired renal function leads to accumulation of MPAG (Fig. 2b). Accumulating MPAG concentrations result in increased transport of MPAG to the gallbladder, leading to increased recirculation of MPAG to MPA. Because of the extra recirculation, MPAG does not accumulate to an extent where it can displace MPA from its protein binding sites. The result is increased tMPA and fMPA (Fig. 9) due to extra recirculation and no change in unbound fraction of MPA. In patients cotreated with cyclosporine, the accumulated MPAG following impaired renal function can not be compensated for by increased 

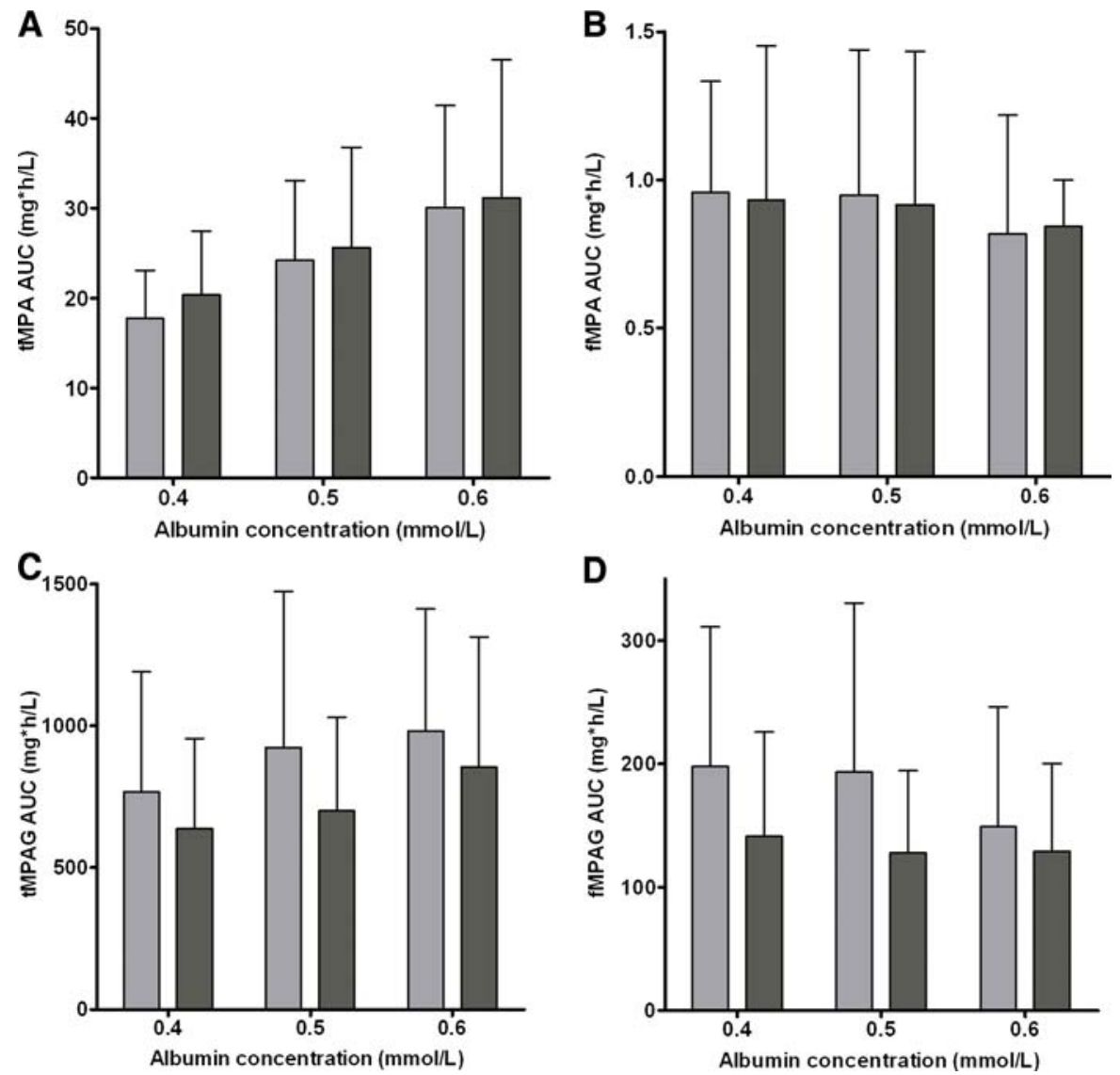

Fig. 7 Influence of albumin concentrations on exposure of a tMPA, b fMPA, c tMPAG and d fMPAG for patients cotreated with CsA (light) or tacrolimus (dark). AUCs are presented as mean and $95 \%$ confidence interval of 50 simulated patients

recirculation because cyclosporine minimizes EHC due to inhibition of MRP2 [20]. As a result MPAG displaces MPA from its protein binding sites, leading to an increased unbound fraction of MPA (Fig. 10) [11, 35]. The increased fMPA exposure is immediately compensated for by an increase in MPA glucuronidation as MPA is a drug with a low extraction ratio [40]. The result is decreased tMPA exposure, unchanged fMPA exposure and an increased MPA unbound fraction. The simulated effects of CrCL on exposure to tMPA and FMPA in patients treated with cyclosporine or tacrolimus are in accordance with previously published results [10, 31, 41, 42].

In vitro analysis showed that fMPA is the pharmacologically active compound, which is responsible for inhibition of IMPDH [27]. Patients with elevated fMPA exposure have an increased risk for leucopenia and infections [23, 24]. However, although a relationship between fMPA exposure and the risk for acute rejection 

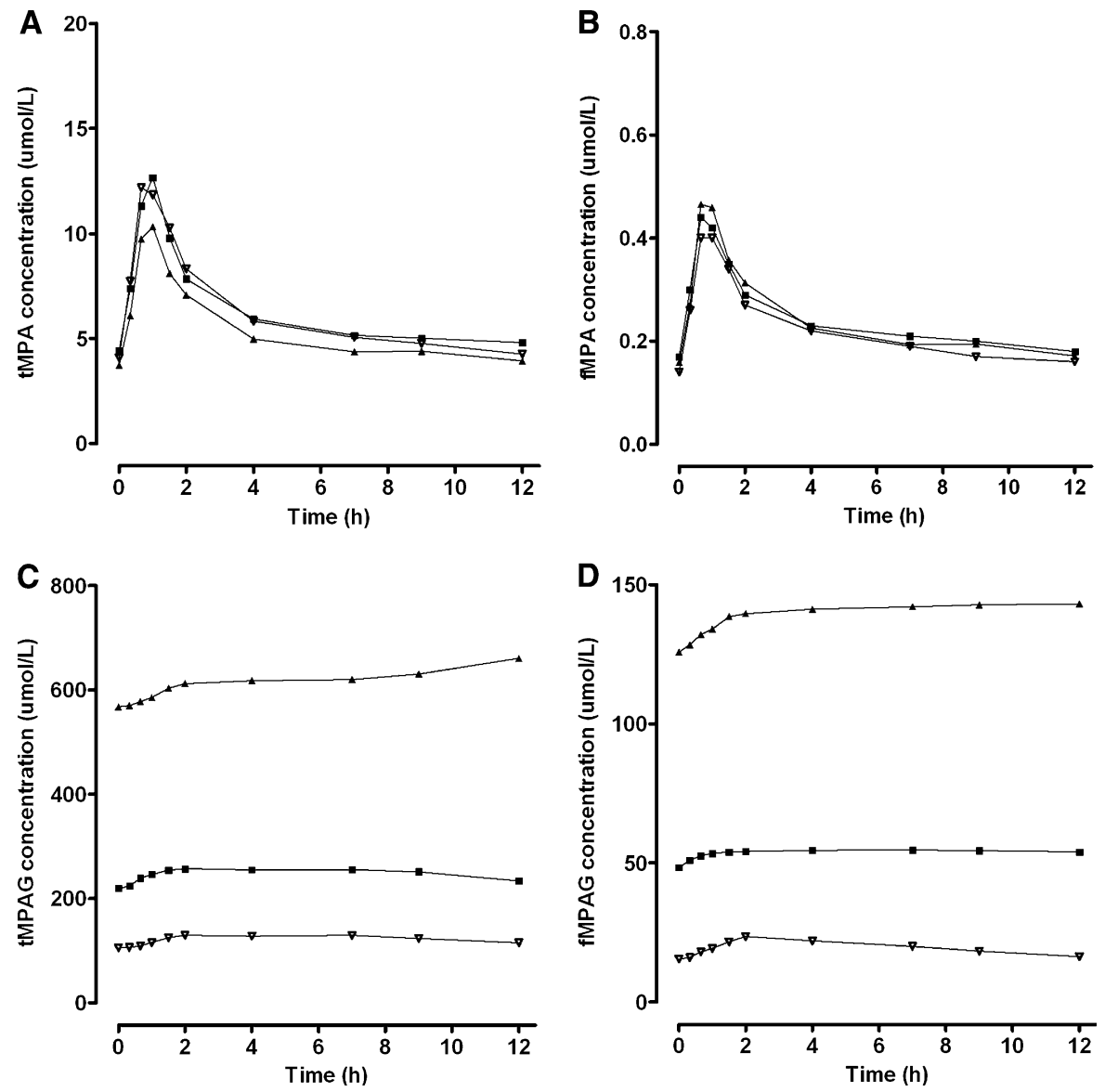

Fig. 8 Influence of creatinine clearance on pharmacokinetic profiles. Median concentration-time profiles of a tMPA, b fMPA, c tMPAG, and $\mathbf{d}$ fMPAG in patients cotreated with CsA and concentration-time profiles of e tMPA, f fMPA, $\mathbf{g}$ tMPAG, and $\mathbf{h}$ fMPAG in patients cotreated with tacrolimus. Concentration-time profiles were simulated for 50 patients with $\mathrm{CrCL}$ of (filled triangle) $10 \mathrm{ml} / \mathrm{min}$, (filled square) $30 \mathrm{ml} / \mathrm{min}$ and (inverted triangle) $50 \mathrm{ml} / \mathrm{min}$

should be expected, it has not been demonstrated yet. On the other hand, a correlation between tMPA exposure and the risk for acute rejection has been reported [6, 21, 22]. Clearly, more information is needed about the relationship between fMPA exposure and the risk for acute rejection and side effects to interpret the clinical effect of changes in protein binding of MPA. In general, fMPA is thought to be responsible for the immunosuppressive effect $[8,9,27]$ and changes in fMPA are supposed to be clinically relevant. Alterations in both albumin concentrations and renal function have little effect on fMPA AUC and have thereby little clinical relevance. However, special attention is necessary in patients with impaired renal function cotreated with tacrolimus as the increased fMPAG can cause elevated exposure to both tMPA and fMPA. 

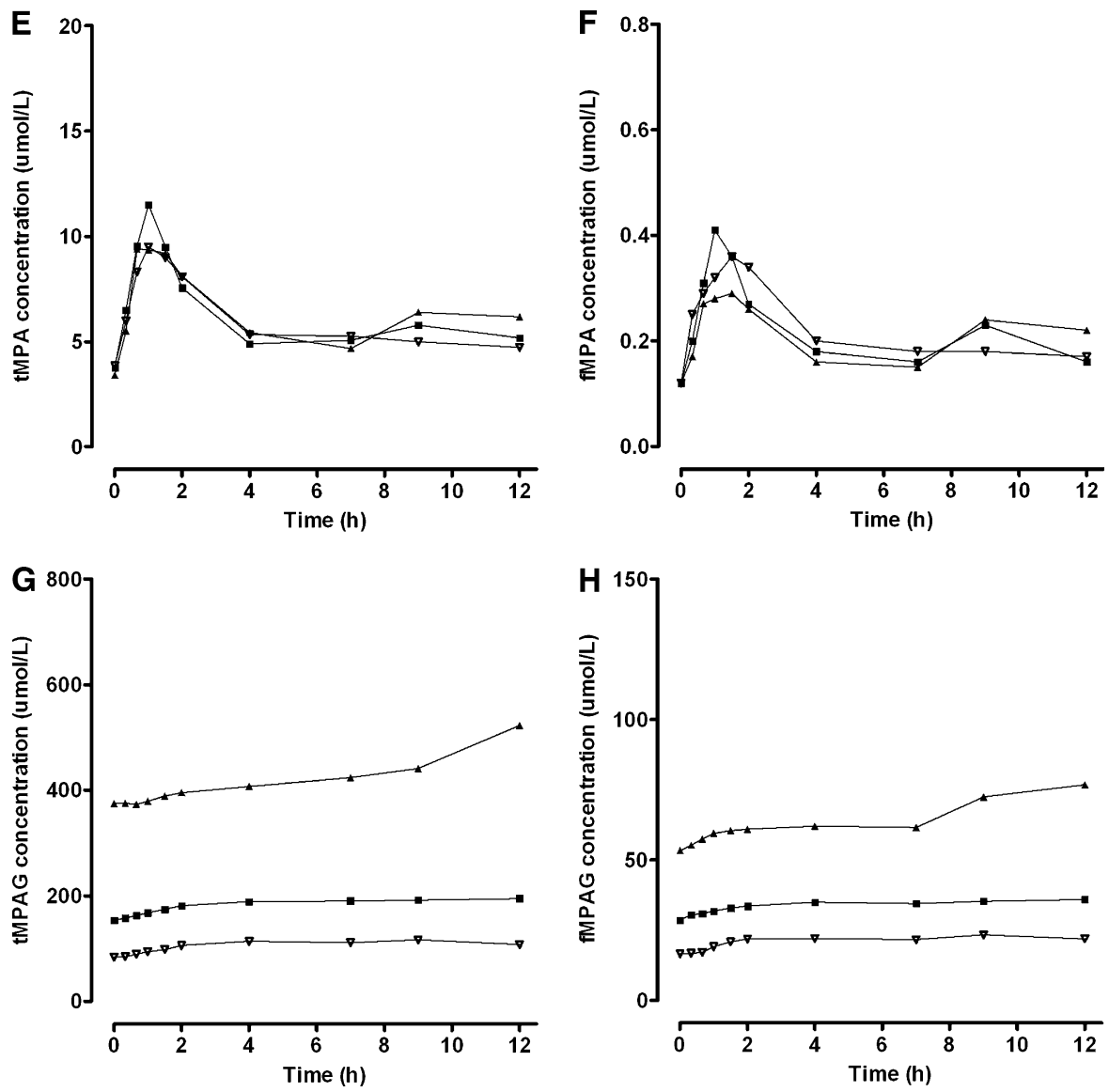

Fig. 8 continued

In conclusion, this model describes the protein binding of both, MPA and its main metabolite MPAG, and the relationship with albumin concentrations, renal function and cyclosporine. When albumin concentrations decrease, tMPA exposure decreases, but fMPA exposure remains unaffected. The increase in MPAG due to impaired renal function is followed by a decrease in tMPA in patients cotreated with cyclosporine and by an increase in tMPA in patients cotreated with tacrolimus. Again, fMPA exposure is hardly affected by the changes in renal function. Changes in protein binding, caused by alterations in albumin concentrations or renal function, will not or hardly influence the exposure of a patient to the probably active agent fMPA. Therefore, changes in protein binding have little clinical relevance if fMPA is indeed the biologically active fraction. 

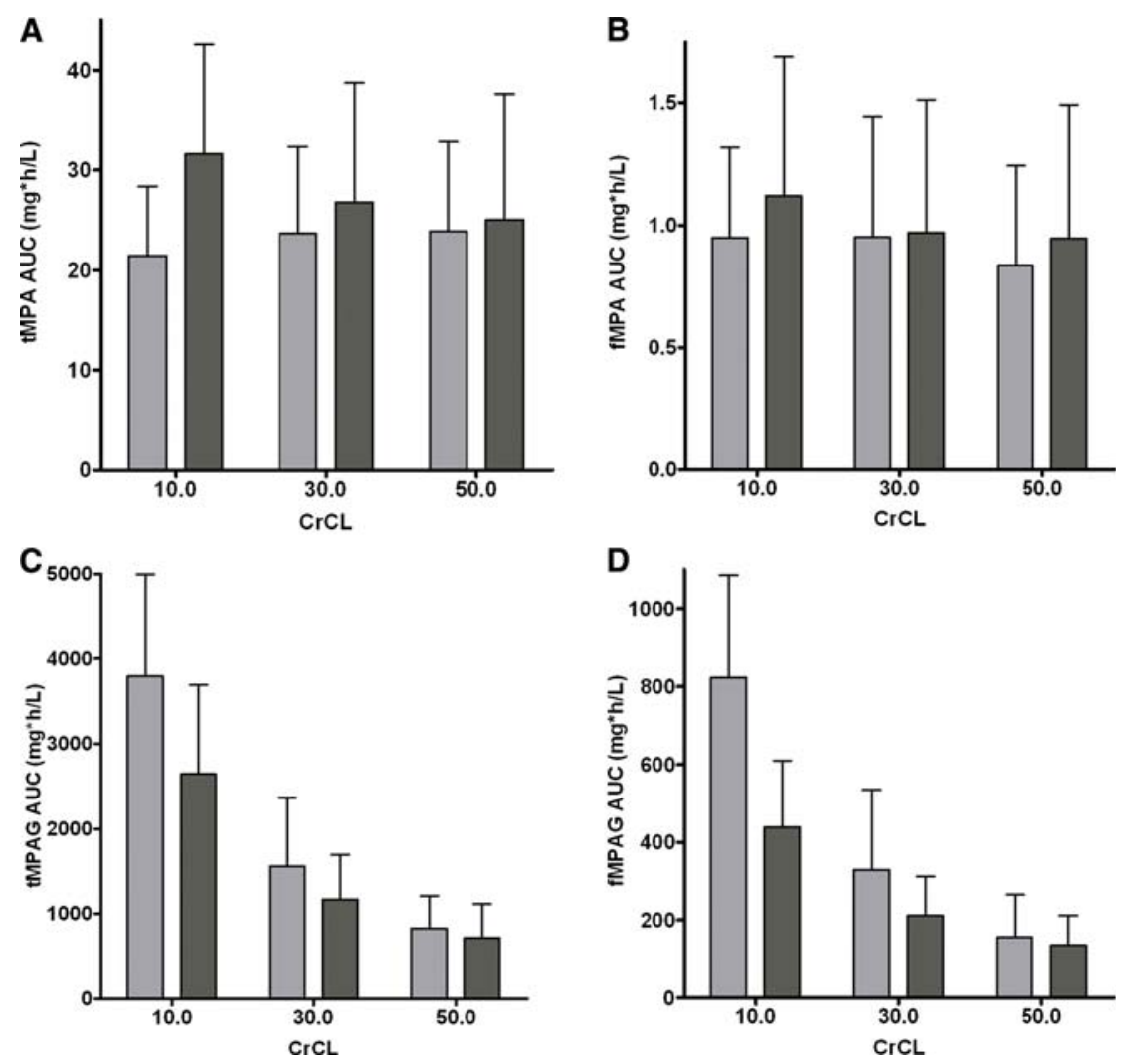

Fig. 9 Influence of creatinine clearance on exposure of a tMPA, b fMPA, $\mathbf{c}$ tMPAG and d fMPAG for patients cotreated with CsA (light) or tacrolimus (dark). AUCs are presented as mean and $95 \%$ confidence interval of 50 simulated patients
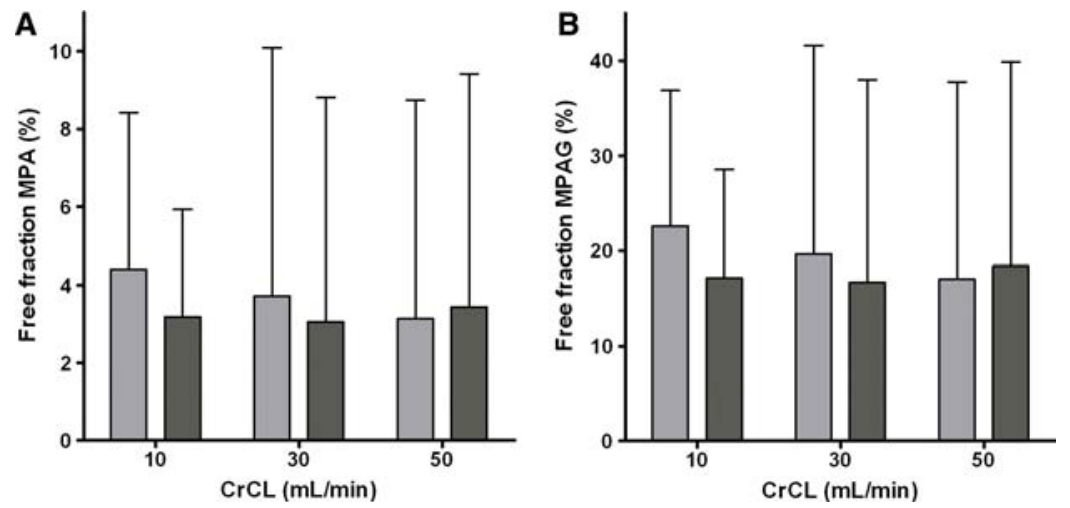

Fig. 10 Influence of CrCL on the free fraction of a MPA and b MPAG. Free fractions are presented as median and 95-percentile interval of 50 simulated patients cotreated with CsA (light) or tacrolimus (dark) 
Open Access This article is distributed under the terms of the Creative Commons Attribution Noncommercial License which permits any noncommercial use, distribution, and reproduction in any medium, provided the original author(s) and source are credited.

\section{References}

1. Knoll G (2008) Trends in kidney transplantation over the past decade. Drugs 68(Suppl 1):3-10

2. Allison AC, Eugui EM (1996) Purine metabolism and immunosuppressive effects of mycophenolate mofetil (MMF). Clin Transplant 10(1 Pt 2):77-84

3. de Winter BC, Mathot RA, van Hest RM, van Gelder T (2007) Therapeutic drug monitoring of mycophenolic acid: does it improve patient outcome? Expert Opin Drug Metab Toxicol 3(2):251-261

4. van Gelder T, Meur YL, Shaw LM, Oellerich M, DeNofrio D, Holt C, Holt DW, Kaplan B, Kuypers D, Meiser B, Toenshoff B, Mamelok RD (2006) Therapeutic drug monitoring of mycophenolate mofetil in transplantation. Ther Drug Monit 28(2):145-154

5. van Gelder T, Silva HT, de Fijter JW, Budde K, Kuypers D, Tyden G, Lohmus A, Sommerer C, Hartmann A, Le Meur Y, Oellerich M, Holt DW, Tonshoff B, Keown P, Campbell S, Mamelok RD (2008) Comparing mycophenolate mofetil regimens for de novo renal transplant recipients: the fixeddose concentration-controlled trial. Transplantation 86(8):1043-1051

6. Le Meur Y, Buchler M, Thierry A, Caillard S, Villemain F, Lavaud S, Etienne I, Westeel PF, de Ligny BH, Rostaing L, Thervet E, Szelag JC, Rerolle JP, Rousseau A, Touchard G, Marquet P (2007) Individualized mycophenolate mofetil dosing based on drug exposure significantly improves patient outcomes after renal transplantation. Am J Transplant 7(11):2496-2503

7. Shaw LM, Holt DW, Oellerich M, Meiser B, van Gelder T (2001) Current issues in therapeutic drug monitoring of mycophenolic acid: report of a roundtable discussion. Ther Drug Monit 23(4):305-315

8. Cox VC, Ensom MH (2003) Mycophenolate mofetil for solid organ transplantation: does the evidence support the need for clinical pharmacokinetic monitoring? Ther Drug Monit 25(2):137-157

9. Bullingham RE, Nicholls AJ, Kamm BR (1998) Clinical pharmacokinetics of mycophenolate mofetil. Clin Pharmacokinet 34(6):429-455

10. van Hest RM, van Gelder T, Vulto AG, Mathot RA (2005) Population pharmacokinetics of mycophenolic acid in renal transplant recipients. Clin Pharmacokinet 44(10):1083-1096

11. Kaplan B, Meier-Kriesche HU, Friedman G, Mulgaonkar S, Gruber S, Korecka M, Brayman KL, Shaw LM (1999) The effect of renal insufficiency on mycophenolic acid protein binding. J Clin Pharmacol 39(7):715-720

12. Kuypers DR, Vanrenterghem Y, Squifflet JP, Mourad M, Abramowicz D, Oellerich M, Armstrong V, Shipkova M, Daems J (2003) Twelve-month evaluation of the clinical pharmacokinetics of total and free mycophenolic acid and its glucuronide metabolites in renal allograft recipients on low dose tacrolimus in combination with mycophenolate mofetil. Ther Drug Monit 25(5):609-622

13. Weber LT, Lamersdorf T, Shipkova M, Niedmann PD, Wiesel M, Zimmerhackl LB, Staskewitz A, Schutz E, Mehls O, Oellerich M, Armstrong VW, Tonshoff B (1999) Area under the plasma concentration-time curve for total, but not for free, mycophenolic acid increases in the stable phase after renal transplantation: a longitudinal study in pediatric patients. German study group on mycophenolate mofetil therapy in pediatric renal transplant recipients. Ther Drug Monit 21(5):498-506

14. Gonzalez-Roncero FM, Gentil MA, Brunet M, Algarra G, Pereira P, Cabello V, Peralvo M (2005) Pharmacokinetics of mycophenolate mofetil in kidney transplant patients with renal insufficiency. Transplant Proc 37(9):3749-3751

15. Shaw LM, Mick R, Nowak I, Korecka M, Brayman KL (1998) Pharmacokinetics of mycophenolic acid in renal transplant patients with delayed graft function. J Clin Pharmacol 38(3):268-275

16. Jiao Z, Zhong JY, Zhang M, Shi XJ, Yu YQ, Lu WY (2007) Total and free mycophenolic acid and its 7-O-glucuronide metabolite in Chinese adult renal transplant patients: pharmacokinetics and application of limited sampling strategies. Eur J Clin Pharmacol 63(1):27-37

17. Johnson AG, Rigby RJ, Taylor PJ, Jones CE, Allen J, Franzen K, Falk MC, Nicol D (1999) The kinetics of mycophenolic acid and its glucuronide metabolite in adult kidney transplant recipients. Clin Pharmacol Ther 66(5):492-500

18. van Gelder T, Klupp J, Barten MJ, Christians U, Morris RE (2001) Comparison of the effects of tacrolimus and cyclosporine on the pharmacokinetics of mycophenolic acid. Ther Drug Monit 23(2):119-128 
19. Filler G, Zimmering M, Mai I (2000) Pharmacokinetics of mycophenolate mofetil are influenced by concomitant immunosuppression. Pediatr Nephrol 14(2):100-104

20. Hesselink DA, van Hest RM, Mathot RA, Bonthuis F, Weimar W, de Bruin RW, van Gelder T (2005) Cyclosporine interacts with mycophenolic acid by inhibiting the multidrug resistance-associated protein 2. Am J Transplant 5(5):987-994

21. Kiberd BA, Lawen J, Fraser AD, Keough-Ryan T, Belitsky P (2004) Early adequate mycophenolic acid exposure is associated with less rejection in kidney transplantation. Am J Transplant 4(7):10791083

22. Hale MD, Nicholls AJ, Bullingham RE, Hene R, Hoitsma A, Squifflet JP, Weimar W, Vanrenterghem Y, Van de Woude FJ, Verpooten GA (1998) The pharmacokinetic-pharmacodynamic relationship for mycophenolate mofetil in renal transplantation. Clin Pharmacol Ther 64(6):672-683

23. Weber LT, Shipkova M, Armstrong VW, Wagner N, Schutz E, Mehls O, Zimmerhackl LB, Oellerich M, Tonshoff B (2002) The pharmacokinetic-pharmacodynamic relationship for total and free mycophenolic Acid in pediatric renal transplant recipients: a report of the german study group on mycophenolate mofetil therapy. J Am Soc Nephrol 13(3):759-768

24. Atcheson BA, Taylor PJ, Mudge DW, Johnson DW, Hawley CM, Campbell SB, Isbel NM, Pillans PI, Tett SE (2005) Mycophenolic acid pharmacokinetics and related outcomes early after renal transplant. Br J Clin Pharmacol 59(3):271-280

25. van Gelder T, Hilbrands LB, Vanrenterghem Y, Weimar W, de Fijter JW, Squifflet JP, Hene RJ, Verpooten GA, Navarro MT, Hale MD, Nicholls AJ (1999) A randomized double-blind, multicenter plasma concentration controlled study of the safety and efficacy of oral mycophenolate mofetil for the prevention of acute rejection after kidney transplantation. Transplantation 68(2):261-266

26. Tsina I, Chu F, Hama K, Kaloostian M, Tam YL, Tarnowski T, Wong B (1996) Manual and automated (robotic) high-performance liquid chromatography methods for the determination of mycophenolic acid and its glucuronide conjugate in human plasma. J Chromatogr B Biomed Appl 675(1):119-129

27. Nowak I, Shaw LM (1995) Mycophenolic acid binding to human serum albumin: characterization and relation to pharmacodynamics. Clin Chem 41(7):1011-1017

28. Sombogaard F, Van Schaik RHN, Mathot RA, Budde K, Van der Werf M, Vulto AG, Weimar W, Glander P, Essioux L, Van Gelder T (2009) Interpatient variability in IMPDH activity in MMFtreated renal transplant patients is correlated with IMPDH type II 3757T $>$ C polymorphism. Pharmacogenet Genomics 19(8):626-634

29. Glander P, Sombogaard F, Budde K, van Gelder T, Hambach P, Liefeldt L, Lorkowski C, Mai M, Neumayer HH, Vulto AG, Mathot RA (2009) Improved assay for the nonradioactive determination of inosine 5'-monophosphate dehydrogenase activity in peripheral blood mononuclear cells. Ther Drug Monit 31(3):351-359

30. Jonsson EN, Karlsson MO (1999) Xpose-an S-PLUS based population pharmacokinetic/pharmacodynamic model building aid for NONMEM. Comput Methods Programs Biomed 58(1):51-64

31. de Winter BC, Neumann I, van Hest RM, van Gelder T, Mathot RA (2009) Limited sampling strategies for therapeutic drug monitoring of mycophenolate mofetil therapy in patients with autoimmune disease. Ther Drug Monit 31(3):382-390

32. Cockroft D, Gault M (1976) Prediction of creatinine clearance from serum creatinine. Nephron $16: 31-41$

33. Jadhav PR, Gobburu JV (2005) A new equivalence based metric for predictive check to qualify mixed-effects models. Aaps J 7(3):E523-E531

34. Atcheson BA, Taylor PJ, Kirkpatrick CM, Duffull SB, Mudge DW, Pillans PI, Johnson DW, Tett SE (2004) Free mycophenolic acid should be monitored in renal transplant recipients with hypoalbuminemia. Ther Drug Monit 26(3):284-286

35. Shaw LM, Korecka M, Aradhye S, Grossman R, Bayer L, Innes C, Cucciara A, Barker C, Naji A, Nicholls A, Brayman K (2000) Mycophenolic acid area under the curve values in African American and Caucasian renal transplant patients are comparable. J Clin Pharmacol 40(6):624-633

36. van Hest RM, van Gelder T, Vulto AG, Shaw LM, Mathot RA (2009) Pharmacokinetic modeling of the plasma protein binding of mycophenolic acid in renal transplant recipients. Clin Pharmacokinet 48(7):463-476

37. Danhof M, Alvan G, Dahl SG, Kuhlmann J, Paintaud G (2005) Mechanism-based pharmacokineticpharmacodynamic modeling-a new classification of biomarkers. Pharm Res 22(9):1432-1437

38. Tillement JP, Lhoste F, Giudicelli JF (1978) Diseases and drug protein binding. Clin Pharmacokinet 3(2):144-154 
39. Benet LZ, Hoener BA (2002) Changes in plasma protein binding have little clinical relevance. Clin Pharmacol Ther 71(3):115-121

40. Bowalgaha K, Miners JO (2001) The glucuronidation of mycophenolic acid by human liver, kidney and jejunum microsomes. Br J Clin Pharmacol 52(5):605-609

41. van Hest RM, Mathot RA, Pescovitz MD, Gordon R, Mamelok RD, van Gelder T (2006) Explaining variability in mycophenolic acid exposure to optimize mycophenolate mofetil dosing: a population pharmacokinetic meta-analysis of mycophenolic acid in renal transplant recipients. J Am Soc Nephrol 17(3):871-880

42. Naesens M, de Loor H, Vanrenterghem Y, Kuypers DR (2007) The impact of renal allograft function on exposure and elimination of mycophenolic acid (MPA) and its metabolite MPA 7-O-glucuronide. Transplantation 84(3):362-373 